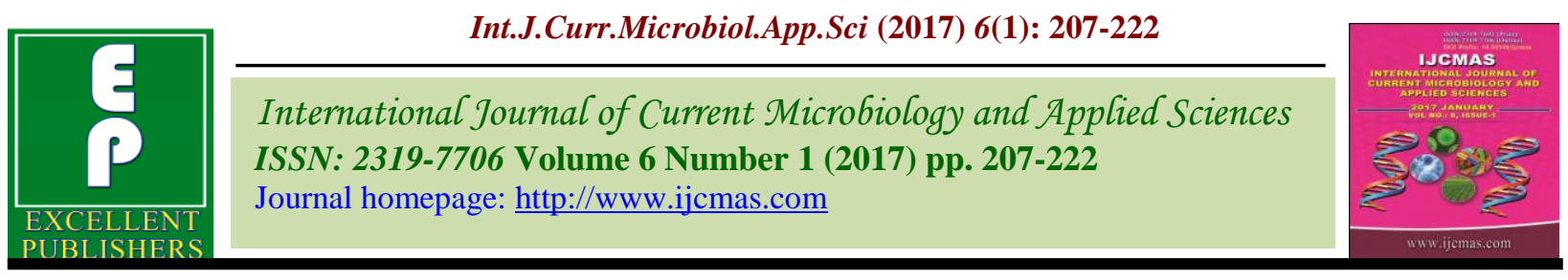

Original Research Article

http://dx.doi.org/10.20546/ijcmas.2017.601.026

\title{
Effect of Refining Process on the Quality Characteristics of Soybean and Cotton seed Oils
}

\author{
Adel Abd EL-Razek Mohdaly, Khaled Abd El-Hameed Seliem, Abd EL-Moneam Maher \\ Abu EL-Hassan* and Awad Abdel Tawab Mahmoud
}

\author{
Food Science and Technology, Faculty of Agriculture, Fayoum University, Egypt \\ *Corresponding author
}

\begin{abstract}
A B S T R A C T
Keywords

Cottonseed Oil,

Fatty Acid,

Physicochemical

Properties, Refining,

Soybean Oil,

Unsaponifiable Matter.

Article Info

Accepted:

12 December 2016

Available Online:

10 January 2017

The objective of this research was to examine changes in physiochemical properties, oxidation indices, phenolic compounds and fatty acid composition during refining of cottonseed oil and soybean oil. 2,2-diphenyl-1-picrylhydrazyl (DPPH) and Rancimat method were used for determination of antioxidant capacities. The results obtained showed that specific gravity have decreased after refining, while refining process does not have a significant effect on the refractive index. Correspondingly, there was reduction in the chemical properties such as acid value, peroxide value, thiobarbituric acid, saponification value and unsaponifiable matter. The refining had a positive effect on the oxidative stability of the oil. Refined cottonseed oil showed relatively higher antioxidant activity by both DPPH and Rancimat methods than refined soybean oil. This study also revealed that the refining process caused approximately $48.8 \%$ and $50 \%$ decrease of total phenolic contents in soybean and cottonseed oils, respectively. There was an increase in the total monounsaturated fatty acids coupled with a significant decrease in the saturated fatty acids in the oil samples after refining process. The loss of bioactive compounds from crude oils is inevitable during the conventional refining processes. Therefore innovations in these oils processing are necessary to produce commercial oil with high antioxidant content.
\end{abstract}

\section{Introduction}

Vegetable oils are an important part of the human diets world-wide and their production by extraction processes greatly increased in the last century due to higher request and consumption, the increase in world population and the progressive availability of more efficient process technologies and equipment.

Edible oils are widely used by food industry due to their nutritional properties and their influence on the smell and taste of food products (Zulkurnain et al., 2012). During the industrial production of vegetable oils and fats by crushing or solvent extraction, various kinds of minor constituents such as dirt, moisture, gums, waxes, color pigments, flavoring substances, phosphates, carbohydrates, protein, pesticide residues, odoriferous materials, trace metals, free fatty acids and the possible residual content of the solvent used for the extraction process are incorporated into triglycerides and may cause the oil to be darkened, foamed, smoked, precipitated, develop off-flavours, decrease thermal and oxidative stability, and increase oil loss (Ghazani et al., 2013). The term crude 
oil is assigned to oil that is not processed after being extracted from the animal or plant material. In order to become suitable for human consumption, crude oils are generally refined to remove the majority of these unwanted components to produce a stable product with desired color and a pleasant taste, with the least possible damages on desirable components and with the least possible loss of oil (Suliman et al., 2013). In general, refined oil is clear, odorless, and resistant to rancidity

The traditional refining process of crude vegetable oils generally includes the steps of degumming, neutralization, bleaching and deodorization. However, during these processes, a large amounts of the micronutrients and antioxidants such as, polyphenols, tocopherols, sterols, carotenoids are lost, which thus reduce substantially the nutritional value and quality of vegetable oils (Szydłowska-Czerniak, 2013).

Cottonseed and soybean oils are among the most unsaturated oils, others being safflower, corn, rapeseed and sunflower seed oils. They are economically important because of their high qualities and quantities of oil. Soybean oil one of the most consumed polyunsaturated vegetable oil worldwide. Alone or in mixture, soybean oil is commonly used for frying as well as for cooking. Soybean oil lie in a group of vegetable oils containing substantial amounts of linolenic acid (C18:3), which is responsible for the development of an offflavour problem known as flavour reversion (Malheiro et al., 2013). Cottonseed oil has a ratio of 2: 1 of polyunsaturated to saturated fatty acids and generally consists of $65-70 \%$ unsaturated fatty acids including 18-24\% monounsaturated (oleic) and $42-52 \%$ polyunsaturated (linoleic) and 26-35\% saturated (palmitic and stearic). Although, specifications for refined oils may differ slightly from those of crude oils due to the prefix added before the biological source of the oil. These refining processes a times modify the chemical properties and constituents of these oils to the point of which could be detrimental to human health hence this work geared towards evaluating the effect of the refining processes on the physicochemical properties, oxidation indices, antioxidant activity and phenolic compounds of soybean and cottonseed oils as well as their fatty acid profile.

\section{Materials and Methods}

\section{Plant material}

Crude and refined soybean and cottonseed oils were obtained from Seilla factory for oils and fat production, Elwatania Factory for oils and soap, Fayoum Governorate, Egypt.

Physicochemical properties of crude and refined oils

\section{Physical constants}

Specific gravity of the samples was measured using a $25 \mathrm{~mL}$ picnometer and a Carl zeiss refractometer was used for measuring the refractive index of the oils (A.O.A.C., 2005). The flow time of the studied oils was measured as an index of viscosity using an Ostwald viscometer for measuring the efflux time in second required to discharge fixed 5 $\mathrm{ml}$ oil at a specified temperature $\left(40^{\circ} \mathrm{C}\right)$. Lovibond equipment was used for determination of color.

\section{Chemical constants}

The iodine value, saponification value, unsaponifiable matter, acid value, and peroxide value were determined according to standard IUPAC methods for the analysis of oils and fats (Dieffenbacher and Pocklington, 1987). The ester value was obtained by subtracting the acid value from the 
saponification value. Thiobarbituric acid (TBA) value as an index of fat oxidation was determined directly on the samples as described by (Egan et al., 1981). All experiments were conducted in triplicate.

\section{Evaluation of Antioxidant Activity}

Determination of DPPH $\quad$ radical scavenging capacity

The method consisted of spectrophotometric measurement of the acuity of the color change in solution depending on the amount of 2,2 diphenyl-1-picrylhydrazyl (DPPH). The reaction was commenced by mixing $3.9 \mathrm{~mL}$ of the methanolic extract with $0.1 \mathrm{~mL}$ of $\mathrm{DPPH}^{\circ}(0.012 \mathrm{~g} / 100 \mathrm{~mL})$. The absorbance at $\lambda_{\max } 517 \mathrm{~nm}$ (UV-visspectronic 2000) was checked at $0,0.5$ and every 0.5 min until the reaction reached a steady state (Suja et al., 2005). The activity of the extract in scavenging $\mathrm{DPPH}^{\circ}$ was calculated as follows:

$\% \mathrm{DPPH}^{*}$ scavenging $=[$ Absorbance of control- Absorbance of sample $] \times 100$

\section{Absorbance of control}

\section{Induction period by Rancimat (stability test)}

The induction periods, as the oxidative stability index, of the tested samples were measured by an automated Rancimat (Metrohm Ltd. CH-9100 Herisau, Switzeland, model 679), comprises of the control unit and the wet section containing 6 reaction vessels, according to the method described by Mendez et al. (1996).

\section{Determination of total phenolic content (TPC)}

The total phenolic content was determined spectrophotometrically using the FolinCiocalteu reagent, according to the procedure described previously by Orwa and Ansam (2104). $10 \mathrm{~g}$ of oils was dissolved in $50 \mathrm{~mL}$ of hexane and extracted three times with $80 \%$ aqueous methanol.The extract was then made up to $100 \mathrm{~mL}$ with water and left to stand overnight. A $1 \mathrm{~mL}$ aliquot of the extract was mixed with $5 \mathrm{ml}$ Folin-Ciocalteus phenol reagent. The mixture was shaken well and let to stand for 5 minutes. Then $1 \mathrm{~mL}$ of saturated sodium carbonate $\left(\mathrm{Na}_{2} \mathrm{CO}_{3}\right)$ was added and after 1 hour at room temperature the absorbance at $725 \mathrm{~nm}$ was measured. Gallic acid was used as standard curve and the results were expressed as mg Gallic acid / $100 \mathrm{~g}$ of oil.

Identification of Unsaponifable matter fraction in oils by Gas Chromatography (GC)

The unsaponifiable fractions were collected and taken to dryness under vacuum. The residue was analyzed using the gas chromatograph HP 5890 (Hewlett Packard) equipped with the MS detector (MSD 5970), EI, 70 ev and fitted with a capillarycolumn DB-1701 (12 m x $0.18 \mathrm{~mm}$ x $0.4 \mathrm{~mm}$; J\&W Scientific). The column temperature was programmed from 260 to $300{ }^{\circ} \mathrm{C}$ while injection temperature was set at $280{ }^{\circ} \mathrm{C}$. Helium was the carrier gas at a flow rate of $0.7 \mathrm{~cm}^{3} / \mathrm{min}$. Identification of peaks was based on the retention time of standard substances and MS spectra. Analyses were run in duplicate. Calculations of percent composition of dimethyl hydrocarbons and dimethylsterol fractions were based on the peak area. 


\section{Analysis of fatty acid composition}

\section{Preparation of Methyl Esters}

Methyl esters of fatty acids were prepared in accordance to the method of Morrison and Smith (1964) with some modification. For sample $100 \mathrm{mg}$ adding $1 \mathrm{~mL} \mathrm{BF}_{3} /$ methanol $(14 \%)$ and $1 \mathrm{~mL}$ hexane. The tube is vortexed and placed under nitrogen for $60 \mathrm{~min}$ at 100 ${ }^{\circ} \mathrm{C}$. Esters of fatty acids were then extracted by adding $1 \mathrm{~mL}$ of hexane and washing with 2 $\mathrm{mL}$ of distilled water. After the centrifugation step (4500 rpm, $10 \mathrm{~min}, 20^{\circ}$ C.), the supernatant is recovered in vials and then injected into the GC column.

\section{Chromatographic analysis of the fatty acid methyl esters}

Methyl esters were analyzed by GC-type CG2010 Plus, Shimadzu, equipped with a flameionization detector and a capillary column of $60 \mathrm{~m}$ length, $0.25 \mathrm{~mm}$ internal diameter, the thickness of the film is 0.20 microns. The oven temperature was $200^{\circ} \mathrm{C}$. The detector and the injector are at a temperature of $250^{\circ} \mathrm{C}$. The samples were separated on the column using helium as the carrier gas with a flow rate of $0.8 \mathrm{~mL} / \mathrm{min}$. The sample is injectedin split mode. The temperature program used in the analysis is to keep the unit at $120^{\circ} \mathrm{C}$ for $2 \mathrm{~min}$ and then climb to $180^{\circ} \mathrm{C}$ for $2 \mathrm{~min}$ and keep the sample at $220^{\circ} \mathrm{C}$ for $25 \mathrm{~min}$. The peak integration is done on thesoftware GC solution (Shimadzu). Peak identification of fatty acids on the chromatogram is made using standard fatty acids (Restek, Food industry FAME Mix methylene chloride $30 \mathrm{mg} / \mathrm{mL}$ ).

\section{Results and Discussion}

\section{Physicochemical properties of the crude} and refined oils

Specific gravity is the heaviness of a substance compared to that of water and it is expressed without units. There was a slightly decrease in the specific gravity of soybean and cottonseed oils during the refining process (Table 1). According to Aluyor et al. (2009), a slight decrease in specific gravity induced by chemical refining may be because of the removal of some polar compounds, gums and some coloring components from the oil by alkali refining, which affected the weight of the oil after refining. These results are in agreement with those mentioned by Guner et al., (2006) who reported that the specific gravity of different refining oils varies with their molecular weights which are affected by refining process involved.

The Refractive Index (RI) is a parameter that relates to molecular weight, fatty acid chain length, degree of unsaturation and degree of conjugation. It is generalized that the refractive indices of oils increases with increase in the number of double bonds. With increase in temperature, the refractive indices of oils decrease. The refractive indices can also be influenced by oxidative damage of the oil. The RI obtained for all oil samples appeared to be approximately the same (Table 1). Hence, refining process does not have a significant effect on the RI of soybean and cottonseed oils. These findings were supported by previous reports of Dalia et al. (2015), who reported that the refractive index was stable throughout the refining. The slightly decrease from $1.4696 \pm 0.002$ to $1.4685 \pm 0.0021$ for soybean oil and from $1.4722 \pm 0.001$ to $1.4690 \pm 0.0035$ for cottonseed oil after refining, may be due to the continuous removal of impurities during the refining process. According to Pearson (1991), the amount of impurities that are contained in the oil affects the degree of reflection caused by a ray of light during refractive index determination. Ogunsina et al. (2014) reported a refractive index of 1.47, almost similar to that found in this study. 
Viscosity of oil is a measure of the oil's resistance to shear. High viscosity implies a high resistance to flow while a low viscosity indicates a low resistance to flow. The results in Table 1 show that there was an increasing in flow time of soybean oil during the refining process, while a slight decrease in flow time from crude cottonseed oil to refined cottonseed oil was observed. Results also showed that the flow time is high in cottonseed oil as compared to soybean oil. It explains that the viscosity and density decreases with an increase in unsaturation and increases with high saturation and polymerization (Kim et al., 2010).

Carotenoids and chlorophyll are the main color pigments found in vegetable oils. Oxidation of these pigments or reaction of oxidized triglycerides with carotenoids may cause oil darkening (Chewa et al., 2016). Moreover, there are many unwanted compounds like FFA, waxes, and phospholipids in oil might promote oxidation and result to undesirable odor and color in the final product. Therefore, one of the concerns in oil refining process is to reduce these color compounds in the crude oils. Neutralization, bleaching and deodorization are steps that neutralize FFA, reduce the yellow pigments and reduced the red pigment, respectively (Wei et al., 2015). As shown in Table 1 the refined oils had a clear with a light golden color compared to those of crude oils. This is due to the effect of refining process on undesirable components.

The quantity of free fatty acids (FFAs), usually referred as "the acid value", is an important determinant of oil quality and has extensively been used as a traditional criterion for classifying olive oil into various commercial grades (Gharby et al., 2015). FFA determination is particularly important for industrial purposes since FFA can modify the organoleptic or physicochemical properties of oil. FFA can act as pro-oxidants in vegetable oils and result in an undesirable taste and flavor (Ghazani et al., 2013). Thus, one of the main objectives of oil refining is to remove FFA from crude oil. As shown in Table 1, the quantity of free fatty acids of crude cottonseed oil were significantly higher than those of the crude soybean oil. This may be due to the fact that the cottonseed oil had been exposed to less suitable conditions of storage and/or a strong enzymatic hydrolysis of cottonseeds during harvesting, handling or oil extraction (Gharby et al., 2014). The acid value of the crude soybean oil $(1.81 \pm 0.11 \mathrm{mg}$ $\mathrm{KOH} / \mathrm{g}$ oil) was almost similar to that reported by Reza et al. (2009) in crude soybean oil (2.09 $\mathrm{mg} \mathrm{KOH} / \mathrm{g}$ oil). The FFA of soybean and cottonseed oils was significantly reduced during the oil refining process with a removal of $91.5 \%$ and $97.5 \%$ of FFA in the crude oils, respectively. It has been reported that there is some decrease in the FFA content after the bleaching and degumming steps, while its major change is observed after the neutralization step, when they are saponified with sodium hydroxide and separated in soap stock . Deodorization is a vacuum-steam distillation at an elevated temperature during which, FFA and volatile odoriferous components can be eliminated in order to produce bland and odorless oil (Reza et al., 2009; Onyema and Ibe 2016). These values in this study are within the ranged specified for edible oils as given by FAO/WHO (2010).

Peroxide value (PV) is used as a measure of the extent to which rancidity reactions have occurred during storage and could be used as an indication of the quality and stability of fats and oils. PV reflected the formation of hydroperoxides that caused by the primary oxidation. It may break down into non volatile secondary product, which decreases the quality of oil. The amount of oxidation products in the soybean and cottonseed oils changed after refining process (Table 1). 
After the refining process, the PV decreased from $12.995 \pm 0.58$ and $3.81 \pm 0.23 \mathrm{meq} \mathrm{O}_{2} / \mathrm{kg}$ to $4.75 \pm 0.26$ and $1.955 \pm 0.05 \mathrm{meq} \mathrm{O}_{2} / \mathrm{kg}$ in soybean and cottonseed oils, respectively. The peroxide value of refined soybean oil (4.75 meq $\mathrm{O}_{2} / \mathrm{kg}$ ) in this study was almost similar to that reported by Ortega-García et al. (2006) in safflower oil (3.56 meq $\left.\mathrm{O}_{2} / \mathrm{kg}\right)$ and Noel et al. (2016) in sesame oil (3.44 meq $\left.\mathrm{O}_{2} / \mathrm{kg}\right)$. The refining has a positive effect on the oxidative stability of the oil. According to Kreps et al. (2014), the refining process removes $79.2 \%$ of hydroperoxides from crude oil. Nzikou et al. (2009) and Anwar et al. (2007) reported peroxide values of 1.67 and $1.27 \mathrm{meq} / \mathrm{kg}$ of soybean oil, respectively; these values are lower than those obtained in the present study. PV is an index of rancidity, thus the high PV of soybean oil indicated their poor resistance to peroxidation during storage. Shahidi and Zhong (2005) and Nyam et al. (2013) noted that the increase in peroxide value might be caused by low temperatures during the last phase of ripening in seeds or by the use of high temperatures in the process of oil extraction or due to the accumulation of hydroperoxides as a result of free radical attacking the unsaturated fatty acids. The results also revealed that cottonseed oil stability to oxidation is relatively better than soybean oil. This is because cottonseed oil includes high level of linoleic acid (18:2n -6) content but soybean oil is rich in $\alpha$-linolenic acid (18:3n -3) in addition to linoleic acid (Table 4). These results indicate that oils with high linolenic contents have low oxidative stabilities. These values in the present study are in line with the standard specified by FAO/WHO (2010) for fresh edible oil, which is below 10 meq $\mathrm{O}_{2} / \mathrm{kg}$.

The saponification value (SV) describes the average molecular weight of the fatty acids in the lipids. Table 1 shows the SV of both the crude and refined oil samples under investigation. Slight decrease in saponification values could be noticed after the refining process for cottonseed oil, while soybean oil exhibited a little change with regards to the refining of the oil. These results are in agreement with those of Onyema and Ibe (2016) who noted that the saponification value decreased with the progression of the oils from crude to refined state. The decrease is understandable with the purification of the oil as the percentage free fatty acids and other fatty components with high molecular weight in the oil being reduced during refining (Chawla, 2003).

The ester value is calculated by subtracting the acid value of oil from the saponification value of the corresponding oils. It is found that in Table 1 the ester values showed a pattern in good agreement with that of the SV.

The determination of iodine is useful as a measure of the degree of unsaturation of the oils and to give some idea of their oxidative stability. High iodine-value oil contains a greater number of double bonds than low iodine-value oil and has usually a reduced oxidative stability. The changes of iodine value (IV) of the soybean and cottonseed oils are presented in Table 1. The iodine value obtained for soybean and cottonseed oils has increased during the refining process; this was an indication that the degree of unsaturation increases progressively as a result of refining. These findings are not supported by previous reports of Dalia et al. (2015), who reported that the iodine content was stable throughout the refining.

Unsaponifable matter (USM) contributes to the stability of edible oil and fatty food through their antioxidant activity. The unsaponifiable matter of the crude and refined oils is showed in Table (1). The unsaponifiable matter decreased from $1.13 \%$ to $0.84 \%$ for crude and refined cottonseed oil respectively and $0.86 \%$ to $0.43 \%$ for crude 
and refined soybean oil respectively after refining, because virtually all the refining processes lead to reduction in the unsaponifiable matter. Our results are in discordance with those obtained by Onyema and Ibe (2016) who found that the unsaponifiable matter in soybean oil increased after refining.

The oxidative state of any vegetable oil can be evaluated from the combined analysis of its peroxide value and thiobarbituric acid (TBA) which indicates the presence of primary and secondary oxidation products, respectively (Gharby et al., 2014).

As shown in Fig. 1, the contents of TBA decreased also during the refining process from 0.076 to 0.056 malonaldehyde absorbance $/ \mathrm{kg}$ for crude and refined soybean oil respectively and 0.998 to 0.043 malonaldehyde absorbance/ $\mathrm{kg}$ for crude and refined cottonseed oil respectively. In general, the refined oils of the present study contain relatively low absorbance value which indicates a slow production of secondary oxidative products thereby greater stability in terms of the secondary oxidation.

\section{Evaluation of antioxidant activity of oil samples}

\section{DPPH radical-scavenging activity}

In the present study, influence of the refining processes on antioxidant activity of soybean and cottonseed oils have been evaluated by DPPH. DPPH ${ }^{*}$ is considered to be a model of a stable lipophilic radical with deep violet colour. Antioxidants react with DPPH', reducing the number of $\mathrm{DPPH}^{*}$ free radicals equal to the number of their available hydroxyl groups. Therefore, the absorption at $517 \mathrm{~nm}$ is proportional to the amount of residual $\mathrm{DPPH}^{\circ}$. The scavenging activity of soybean and cottonseed oils against $\mathrm{DPPH}^{\circ}$ was concentration-dependent (Fig. 2). Refined cottonseed oil showed relatively high antioxidant activity than refined soybean oil at all the concentrations; this is might be due to the considerably higher level of unsaponifiable matter in refined cottonseed oil. The refined oils were considerably less effective radical-scavengers than the crude oils, indicating that antioxidants or active compounds could be removed during refining process.

\section{Rancimat method}

The susceptibility of crude and refined oils to oxidation was measured by the wellestablished Rancimat method and expressed as induction period (Gharby et al., 2015). The Rancimat method is an accelerated aging test and a commonly used procedure in the food industry for the examination of the oxidative stability of edible oils and prediction of their shelf life. Rancimat results, due to the formation of secondary reaction products (Table 2), showed a pattern in good agreement with that of DPPH methods. As can be seen in Table 2, induction period of crude soybean oil was (24.6), while it was (21.18) for crude cottonseed oil.

The high oxidative stability of the crude oils may be due to their higher level of natural antioxidants, phenolic compounds and phosphatides that have synergistic effects on antioxidants (Taylor, 2005). On the other hand, the induction period of refined soybean and cottonseed oils were 1.90 and 2.30, respectively. These reductions in oxidative stability after refining process might be due to degumming and neutralization steps which remove these active compounds. Barriuso et al., (2013) reported that phospholipid content of soybean oil reduced from $1-3 \%$ to essentially zero after degumming and alkali refining steps. 


\section{Total phenolic content}

Total phenolic contents (TPC) were determined by using Folin-Ciocalteu reagent (FCR). Folin-Ciocalteu reagent reacts nonspecifically with phenolic compounds as it can be reduced by a number of non phenolic compounds. The amount of total phenolics determined in crude and refined oils is shown in Table 2. It is notable that the refining process caused approximately $48.8 \%$ and $50 \%$ decrease of TPC in soybean and cottonseed oils, respectively. For comparison, in the work of Aleksandra et al., (2011), the refining process caused approximately from $26 \%$ to $55 \%$ decrease of TPC in palm oil. This is might due to the unstable of phenolic compounds during the oil refining process with heat treatment applied. SzydłowskaCzerniak et al., (2008) observed that the highest losses of TPC occurred in the neutralization step of the rapeseed and soybean oil refining $(40 \%$ and $64 \%$, respectively). However, the amounts of total phenolic compounds in the refined cottonseed oil were about 3.5 times lower than the refined soybean oil. Refined cottonseed oil showed relatively high antioxidant activity by both DPPH and Rancimat methods than refined soybean oil. This is because antioxidant activity could not be predicted on the basis of the TPC only due to the synergism of polyphenolic compound with one another or with other components present in the sample with antioxidant potential that may contribute to the overall observed antioxidant activity (Ordonez et al., 2005). These findings are in close agreement with previous findings of $\mathrm{Yu}$ et al. (2002) who reported that there is no correlation between the content of these main antioxidant compounds and radical-scavenging capacity.

\section{Minor compounds of crude and refined oils}

Soybean and cottonseed oils, like the majority of crude vegetable oils, contain a variety of minor components which generally constitute the unsaponifiable matter. The unsaponifiable matters present in vegetable oils and fats are usually composed of sterols, fatty alcohols, tocopherols, triterpene alcohols, and hydrocarbon (squalene) which have individual biological importance. Some of the above constituents may exert a pronounced effect on stability of the oils and their nutritional properties. Table 3 shows the changes in phytosterol, fatty alcohols, tocopherol, triterpene alcohols and hydrocarbon contents during the refining process.

In this study, Y-Sitosterols was the most abundant phytosterol in crude soybean and cottonseed oils, followed by campesterol, which agreed with the previous study of Chew et al. (2015). Phytosterols are encouraged to include in the human diet as their ability to lower blood cholesterol and phytosterols possess antibacterial, antiinflammatory, antifungal, and antitumoral activities (Garoufi et al., 2014). Owing to their role in the protection against oxidative deterioration of polyunsaturated fatty acids in plant material, tocopherols in seed oil are extremely important. Tocopherols have inhibitory effect on LDL oxidation and they have several nutritional benefits. Small amounts of hydrocarbons and triterpene alcohols were present in the refined oils. The whole refining process had removed $100 \%$ of the total phytosterol and tocopherols contents in both soybean and cottonseed oils. This could be explained that during industrial processing of oils and fats, sterols undergo dehydration, resulting in the formation of sterenes. Sterenes are formed during bleaching due to acid catalyzed, dehydration on the surface of the acid-activated bleaching earth or due to dehydration promoted by heat during the deodorization process (EL-Mallah et al., 2011). During neutralization, the phytosterols are transferred by liquid-liquid 
partitioning to soap stock (Karabulutet al., 2005). These results are in agreement with the findings of Rossi et al., (2007) who reported the tocopherols are generally themselves first oxidized and are quickly decomposed by oxidation reactions or during the refining process and will therefore be present in a small proportion or essentially zero. On the other hand, our result was different from the previous studies, which showed a reduction in total tocopherol contents during bleaching, neutralization, and deodorization, and this is might due to their possible adsorption on bleaching earth, the tocopherol are unstable in the presence of oxygen and strong alkali condition, and the tocopherol might distillate under deodorizing conditions respectively (Suliman et al., 2013).
Effect of refining on fatty acids composition of soybean and cottonseed oils

The fatty acids composition is an essential indicator of the nutritional value of the oil. Fatty acids from the crude and refined oils under study were identified and quantified using gas chromatography analyses. The fatty acid profile of crude and refined oils of soybean and cottonseed is presented in Table 4. In general, the oils exhibited a fatty acid profile with linoleic acid (C18:2n6) as the most prevalent fatty acid. The high percentage of linoleic acid recommended that these oils could be used as good sources of essential fatty acid due to their ability to reduce serum cholesterol and LDL level (Nyam et al., 2009).

Table.1 Physicochemical properties of crude and refined soybean and cottonseed oilsa

\begin{tabular}{|c|c|c|c|c|}
\hline Parameter & $\begin{array}{c}\text { Crude } \\
\text { soybean oil }\end{array}$ & $\begin{array}{c}\text { Refined } \\
\text { soybean oil }\end{array}$ & $\begin{array}{c}\text { Crude } \\
\text { cottonseed oil }\end{array}$ & $\begin{array}{c}\text { Refined } \\
\text { cottonseed oil }\end{array}$ \\
\hline Specific gravity & $0.9192 \pm 0.002$ & $0.9167 \pm 0.004$ & $0.9385 \pm 0.0030$ & $0.9067 \pm 0.003$ \\
\hline Refractive Index (RI) & $1.4696 \pm 0.002$ & $1.4685 \pm 0.0021$ & $1.4722 \pm 0.001$ & $1.4690 \pm 0.0035$ \\
\hline Flow Time (Sec.) & $4.885 \pm 0.007$ & $6.250 \pm 0.042$ & $7.815 \pm 0.22$ & $7.290 \pm 0.099$ \\
\hline Color & $8 / 35$ & $1.3 / 18$ & $12 / 35$ & $8.5 / 35$ \\
\hline $\begin{array}{c}\text { Acid value (A.V) (mg } \\
\text { KOH / g oil) }\end{array}$ & $1.81 \pm 0.11$ & $0.145 \pm 0.007$ & $6.11 \pm 0.10$ & $0.135 \pm 0.01$ \\
\hline $\begin{array}{c}\text { Peroxide value (P. V) } \\
\text { (meq O / kg oil) }\end{array}$ & $12.995 \pm 0.58$ & $4.75 \pm 0.26$ & $3.81 \pm 0.23$ & $1.955 \pm 0.05$ \\
\hline $\begin{array}{c}\text { Saponification value (mg } \\
\text { /g oil) }\end{array}$ & $172.99 \pm 0.91$ & $171.11 \pm 0.72$ & $180.78 \pm 0.01$ & $168.075 \pm 2.91$ \\
\hline $\begin{array}{c}\text { Ester value (mg / g oil) } \\
\text { (modine value (IV) } \\
\text { (g I / 100 g of oil) }\end{array}$ & $171.18 \pm 2.46$ & $170.97 \pm 0.73$ & $174.67 \pm 0.11$ & $167.94 \pm 2.91$ \\
\hline $\begin{array}{c}\text { Unsaponifiable matter } \\
\text { (\%) }\end{array}$ & $0.86 \pm 0.005$ & $0.43 \pm 0.002$ & $1.13 \pm 0.01$ & $0.84 \pm 0.012$ \\
\hline
\end{tabular}

*Each value represents mean \pm SD of three replicates. 
Table.2 Oxidative stability and total phenolic content of oil samples

\begin{tabular}{|c|c|c|}
\hline Sample & $\begin{array}{c}\text { Oxidative stability } \\
\text { (Induction Period / hr. })\end{array}$ & $\begin{array}{c}\text { Total phenolic content }^{\mathbf{a}} \\
\text { (mg Gallic acid / 100 g of oil) }\end{array}$ \\
\hline Crude soybean oil & 24.60 & $64.37 \pm 0.54$ \\
\hline Refined soybean oil & 1.90 & $32.94 \pm 0.92$ \\
\hline Crude cottonseed oil & 21.18 & $19.73 \pm 0.27$ \\
\hline Refined cottonseed oil & 2.30 & $9.87 \pm 0.18$ \\
\hline
\end{tabular}

${ }^{\mathrm{a}}$ Each value represents mean $\pm \mathrm{SD}$ of three replicates

Table.3 Identification of unsaponifiable matters of crude and refined oils using GC-MS analysis.

\begin{tabular}{|c|c|c|c|c|}
\hline $\begin{array}{l}\text { Components } \\
\text { Identified }\end{array}$ & $\begin{array}{c}\text { Crude } \\
\text { cottonseed oil }\end{array}$ & $\begin{array}{l}\text { Refined } \\
\text { cottonseed oil }\end{array}$ & $\begin{array}{c}\text { Crude } \\
\text { soybean oil }\end{array}$ & $\begin{array}{c}\text { Refined } \\
\text { soybean oil }\end{array}$ \\
\hline \multicolumn{5}{|l|}{ Phytosterols } \\
\hline Campesterol & 2.550 & nd & 2.601 & nd \\
\hline Stigmasterol & nd & nd & 2.328 & nd \\
\hline Y-Sitosterols & 31.965 & nd & 7.853 & nd \\
\hline Pyracholestrobine & nd & nd & 0.650 & nd \\
\hline \multicolumn{5}{|l|}{ Hydrocarbon } \\
\hline Hexadecanoic acid & 1.262 & nd & 2.546 & nd \\
\hline Heptacosan & nd & 1.185 & nd & 1.780 \\
\hline Hexacosane & nd & nd & nd & 2.290 \\
\hline Octadecanoic acid & nd & 1.232 & 6.832 & nd \\
\hline 1-Nonadecene & 1.547 & nd & 3.955 & nd \\
\hline 1-docosene & 1.552 & nd & 0.524 & nd \\
\hline Pentatriacontene & 1.262 & nd & nd & 0.726 \\
\hline Tochopherols & 0.947 & nd & nd & nd \\
\hline \multicolumn{5}{|l|}{ Phenols } \\
\hline Epoxiconazole & nd & nd & 2.776 & nd \\
\hline \multicolumn{5}{|l|}{ Triterpene alcohols } \\
\hline 1-Tetracosanol & nd & nd & 0.087 & nd \\
\hline Octadecanal & 1.182 & 1.182 & nd & 0.598 \\
\hline Octatriacontanol & 1.142 & nd & nd & nd \\
\hline Hexsadecanol & 1.480 & nd & nd & nd \\
\hline 1-Dodecanol & 1.102 & nd & nd & nd \\
\hline
\end{tabular}

nd: not detected 
Table.4 Fatty acid composition (\%) of crude and refined soybean and cottonseed oils

\begin{tabular}{|l|c|c|c|c|}
\hline \multicolumn{1}{|c|}{ Compounds } & $\begin{array}{c}\text { Crude } \\
\text { cottonseed oil }\end{array}$ & $\begin{array}{c}\text { Refined } \\
\text { cottonseed oil }\end{array}$ & $\begin{array}{c}\text { Crude } \\
\text { soybean oil }\end{array}$ & $\begin{array}{c}\text { Refined } \\
\text { soybean oil }\end{array}$ \\
\hline C14 Myristic & 0.66 & 0.06 & 0.08 & 0.08 \\
\hline C16 Palmitic & 24.55 & 6.46 & 10.69 & 8.38 \\
\hline C16:1 Palmitoleic & 0.66 & 0.07 & 4.37 & 4.42 \\
\hline C17 Margaric & 0.19 & nd & 0.08 & nd \\
\hline C18 Stearic & 0.21 & 3.46 & 4.12 & 4.12 \\
\hline C18:1 n9 cis Oleic & 19.05 & 24.39 & 21.64 & 28.53 \\
\hline C18:1 n9 t Elaidic & 2.10 & nd & nd & nd \\
\hline C18:2 n6 cis Linoleic & 51.54 & 64.30 & 41.08 & 37.14 \\
\hline C18:3 n3 Linolenic & 0.19 & 0.33 & 15.92 & 12.73 \\
\hline C20 arachidic & 0.21 & $n d$ & 0.03 & 0.14 \\
\hline C20:1 n-9 Gondoic & 0.12 & 0.07 & 1.49 & 1.86 \\
\hline C22 Behenic acid & 0.17 & 0.56 & 0.27 & 0.15 \\
\hline Unknown compound & 0.34 & 0.31 & 0.25 & 2.45 \\
\hline Total SFA & 26.00 & 10.54 & 15.26 & 12.87 \\
\hline Total unsaturated & 73.66 & 89.15 & 84.49 & 84.68 \\
\hline Total MUFA & 21.93 & 24.52 & 27.49 & 34.82 \\
\hline Total PUFA & 51.73 & 64.63 & 57.00 & 49.86 \\
\hline SFA /UnSFA & 0.35 & 0.12 & 0.18 & 0.15 \\
\hline
\end{tabular}

${ }^{\mathrm{a}}$ Results are expressed as percentage of the total fatty acids.

SFA: saturated fatty acids, MUFA: monounsaturated fatty acids, PUFA: polyunsaturated fatty acids, UnSFA: unsaturated fatty acids, nd: not detected

Fig.1 TBA value (as absorbance at $517 \mathrm{~nm}$ ) of oils

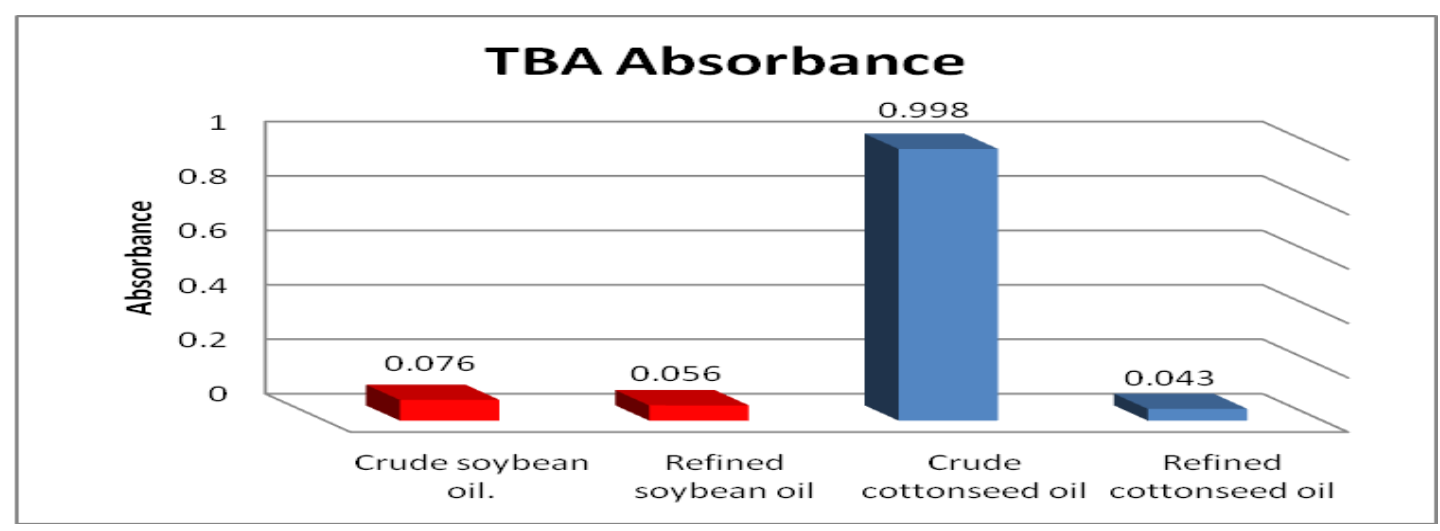


Fig.2 Scavenging activity of crude and refined soybean and cotton seed oils at different concentrations.

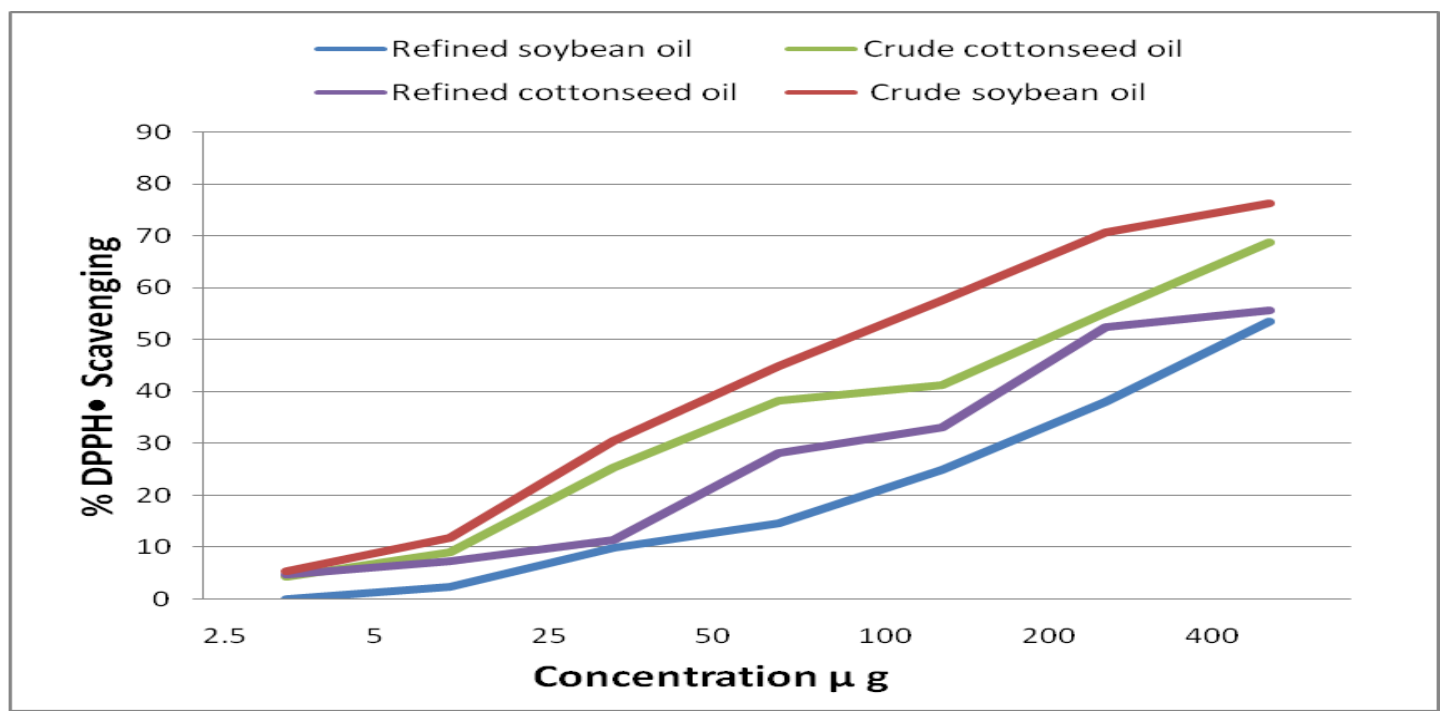

Previous studies showed that the refining process did not have a significant effect on the fatty acid composition of hazelnut oil and groundnut oil (Aluyor et al., 2009). The results obtained by us do not support these claim, which a significant increase in the total monounsaturated fatty acids (MUFA) coupled with a significant decrease in the saturated fatty acids in the oil samples after the refining process were shown in the present work. Budiadnyani et al., (2015) were reported that the saturated fatty acids in by product fish oil of tuna meal processing were decreased also during the refining process from $36.8 \%$ to $31.9 \%$. The oils under study are highly unsaturated, with total polyunsaturated fatty acids (PUFA) ranged between $49.86 \%$ (refined soybean oil) and $64.63 \%$ (refined cottonseed oil). There was a slight decrease in linolenic acid (C18:3n3) in refined soybean oil compared to crude oil, while the oleic acid contents for both soybean and cottonseed oils have increased during the refining process.

Moderate amounts of palmitic acid were present in the refined soybean and cottonseed oils. A slight decrease in linolenic acid might be due to the oxidation at a higher temperature during the refining process caused to the increase in oleic acid (BachariSaleh et al., 2013). The presence of high content of oleic acid in the refined oil samples make them desirable in terms of nutrition and high stability to act as cooking and frying oil. Besides that, a moderate level of palmitic acid is needed for the production of margarine, shortening and other fat products (Coetzee et al., 2008). The ratio of saturated fatty acids to unsaturated fatty acids in refined oil samples was found 0.12 and 0.15 , which clearly indicated the high amount of unsaturated fatty acids and can be positively considered from the nutritional point of view

In conclusion, refining is a necessary process to make a vegetable oil suitable for human consumption. In the present study, the impact of refining process on the physicochemical properties, antioxidant activity and bioactive compounds of soybean and cottonseed oils as well as their fatty acid profile were studied. Evidently, refining processes have more significant changes to chemical properties of the vegetable oils investigated than the physical parameter. Basically, the change is seen to be a general reduction in the chemical 
properties is encouraged as they lead to the improvement on the quality of the refined oil. However, physical properties enjoy little or no effect while overlooking colour with significant reduction. While commending this, the decrease in the unsaponifiable matter is highly unacceptable to some extent though it increases refining losses, its overall importance cannot be overemphasized. Hence, methods for isolation of these unsaponifiable matter should be devised and attached to the refining system to reintroduce them to the oil while limiting their refining effects due to its importance (stability, nutrition, medicine) which cannot be neglected.

\section{References}

A.O.A.C. 2005. Association of Official Analytical Chemists. 18th Edition, Maryland, USA.

Aleksandra, S., Konrad, T., Gyorgy, K. and Edward, S. 2011. Effect of refining processes on antioxidant capacity, total contents of phenolics and carotenoids in palm oils. Food Chemistry, 129: 11871192.

Aluyor, E.O., Aluyor, P., and Ozigagu, C.E. 2009. Effect of refining on the quality andcomposition of groundnut oil. African J. Food Sci., 8(3): 201-205.

Anwar, F., Shahzad, A., Shahid, C. and Abdullah, I. 2007. Assessment of oxidative deterioration of soybean oil at ambient and sunlight storage. Grasasy aceites, 58 (4): 390-395.

Bachari-Saleh, Z., Ezzatpanah, H., Aminafshar, M. and Safafar, H. 2013. The effect ofrefining process on the conjugated dienes in soybean oil. $J$. Agri. Sci. Technol., 15: 1185-1193.

Barriuso, B., Astiasaran, I. and Ansorena, D. 2013. Areview of analytical methods measuring lipid oxidation status in foods. European Food Res. Technol.,
236: 1-15.

Budiadnyani, I.G.A., Estiasih, T. and Yunianta, A. 2015. Characteristics and fatty acidprofile of refined fish oil from byproduct of yellowfin tuna (Thunnus albacores)meal processing. J. Life Sci. Biomed., 5 (5): 132-136.

Chawla, S. A. 2003. Textbook of Engineering Chemistry (3rd ed.). Dhanpat Rai \& Co. (P) Ltd Educational and Technical Publishers, Delhi, 81- 88.

Chew, S.C., Tan, C.P., Long, K. and Nyam, K.L. 2015. In-vitro evaluation of kenaf seed oilin chitosan coated-high methoxyl pectin-alginate microcapsules. Industrial Crops and Products, 76: 230-236.

Chewa, C. T., Kamariah, L. and Kar-Lin, N. 2016. Effect of chemical refining on the quality of kenaf (hibiscuscannabinus) seed oil. Industrial Crops and Products, 89: 59-65.

Coetzee, R., Labuschagne, M.T. and Hugo, A. 2008. Fatty acid and oil variation in seedfrom kenaf (Hibiscus cannabinus L.). Industrial Crops and Products, 27: 104-109.

Dalia, I.S., Jaime, L., Jose, A. N., Gabriela, S.M., Julia, L. and Perfecto, P. 2015. Effect of the refining process on Moringa oleifera seed oil quality. Food Chem., 187: 53-57.

Dieffenbacher, A. and Pocklington, W.D. 1987. Standard methods for the analysis of oils, fats and derivatives. International Union of Pure and Applied Chemistry, 7th ed., Oxford: Blackwell Scientific.

Egan, H., Kirk, R.S., Sawyer, R. and Pearson, D. 1981. Pearson's chemical analysis of foods. $8^{\text {th }} \mathrm{Edn}$. , Churchill Livingstone.: 537.

El-Mallah, H.M., Safinaz, M., Minar, M. M. and Adel, G. 2011. Effect of chemical refining steps on the minor and major components of cottonseed oil. 
Agriculture and Biol. J. North America, 2 (2): 341-349.

FAO/WHO. (2010) Fats and Fatty Acids in Human Nutrition. Report of an Expert Consultation; FAO/WHO: Geneva, Switzerland.

Garoufi, A., Vorre, S., Soldatou, A., Tsentidis, C., Kossiva, L., Drakatos, A., Marmarinos, A. and Gourgiotis, D. 2014. Plant sterols-enriched diet decreases small, dense LDL-cholesterol levels in children with hypercholesterolemia: aprospective study. Italian J. Pediatrics, 40 (42): 16.

Gharby, S., Harhar, H., Bouzoubaa, Z., Asdadi, A., El Yadini,A.and Charrouf, Z. 2015.Chemical characterization and oxidative stability of seeds and oil of sesame grown in Morocco. J. Saudi Society of Agricultural Sci., (in press) http://dx.doi.org/10.1016/j.jssas.2015.03 .004 .

Gharby, S., Harhar, H., Guillaume, D., Roudani, A., Boulbaroud, S., Ibrahimi, M., Ahmad, M., Sultana, S., Ben Hadda, T., Chafchaouni-Moussaoui, I. and Charrouf, Z. 2014. Chemical Investigation of Nigella sativa L. Seed Oil Produced in Morocco. J. Saudi Society of Agricultural Sci., (in press). http://dx.doi.org/10.1016/j.jssas. 2013.12.001.

Ghazani, S. M., Garcia-Llatas, G. and Marangoni, A. G. 2013. Minor constituents in canola oil processed by traditional and minimal refining methods. J. American Oil Chemists' Society, 90: 743-756.

Guner, F.S., Yusuf, Y., Erciyes, A.T., (2006) Polymeres from triglyceride oils. Progress in Organic Coatings, 31: 633670.

Karabulut, I., Topcu, A., Yorulmaz, A., Tekin, A. and Ozay, D.S. 2005. Effect of the industrial refining process on some properties of hazelnut oil. European J. Lipid Sci. Technol., 107: 476-480.

Kim, M., Yan, S., Salley, S.O. and Ng, K.Y.S. 2010. Competitive transesterification of soybean oil with mixed methanol/ethanol over heterogeneous catalysts. Biores. Technol., 101(12): 4409-4414.

Kreps, F., Vrbikova, L. and Schmidt, S. 2014. Influence of industrial physical refining ontocopherol: chlorophyll and betacarotene content in sunflower and rapeseedoil. European J. Lipid Sci. Technol., 116: 1572-1582.

Malheiro, R., Rodrigues, N., Manzke, G., Bento, A., Pereira, J. A. and Casal, S. 2013.The use of olive leaves and tea extracts as effective antioxidants against the oxidation of soybean oil under microwave heating. Industrial Crops and Products, 44: 37-43.

Mendez, E., Sanhueza, J., Speisky, H., and Valenzuela, A. 1996. Validation of the Rancimat test for the assessment of the relative stability of fish oils. $J$. American Oil Chemists' Society, 73: 1033- 1037.

Morrison, W.R. and Smith, L.M. 1964 Preparation of fatty acid methyl esters and dimethylacetals from lipids with boron fluoride-methanol. J. Lipid Research, 5: 600-608.

Noel, T., Roger, P., Bernard, T., Fabrice, T., Thirupathi, A., Mallampalli, S.L.K., Rachapudi, B.N.P. and Hilaire, M.W. 2016.Effects of boiling and roasting on proximate composition, lipid oxidation, fatty acid profile and mineral content of two sesame varieties commercialized and consumed in Far-North Region of Cameroon. Food Chemistry (in press).

Nyam, K. L., Wong, M. M., Long, K. and Tan, C. P. 2013.Oxidative stability of sunfl ower oils supplemented with kenaf seed extract, roselle seed extract 
and roselle extract, respectively under accelerated storage. The International Food Res. J., 20(2): 695-701.

Nyam,K.L.,Tan,C.P.,Lai,O.M.,Long,K.,andY aakob,C.M. 2009. Physicochemical properties and bioactive compounds of selected seed oils. LWT- Food Sci. Technol., 42: 1396-1403.

Nzikou, M., Matos, L., Bouanga, G.K., Kalou, C.B., Ndangui, N.P., Pambou, A., Kimbonguila, T. Silou, M. L. and Desobry, S. 2009. Chemical composition on the seeds and oil of sesame (Sesamum indicum L.) grown in Congo-Brazzaville. Advance J. Food Sci. Technol., 1: 6-11.

Ogunsina, B.S., Indira, T. N., Bhatnagar, A. S., Radha, C., Sukumar D. and Gopalakrishna, A. G. 2014. Quality characteristics and stability of Moringa oleifera seed oil of Indian origin. $J$. food Sci. Technol., 51: 503-510.

Onyema, C. and Ibe, K. 2016. Effects of Refining Processes on the Physicochemical Properties of Some Selected Vegetable Oils. American Chemical Sci. J., 12(4): 1-7.

Ordonez, A.A.L., Gomez, J.D., Vattuone, M.A. and Isla, M.I. 2005. Antioxidant activites of Sechium edule (Jacq.) Swartz extracts. Food Chemistry, 97: 452-458.

Ortega-Garcia, J., Gamez-Meza, N., NoriegaRodriguez, J.A., Dennis-Quinonez, O., GarciaGalindo, H.S., Angulo-Guerrero, J.O. and Medina-Juarez, L.A. 2006. Refining of high oleic safflower oil: Effect on the sterols and tocopherols content. European Food Res. Technol., 223(6): 775-779.

Orwa, J., and Ansam, Q. 2014. Determination of Total Polyphenolic Antioxidants Contents in West-Bank Olive Oil. $J$. Natural Sci. Res., 4: 15- 23.

Pearson, D. 1991. The chemical analysis of foods.7th Ed. Church Livingstone
Longman group limited,: 490-493.

Reza, F., Seyedeh, Z., and Hoseini, Y. 2014. Evolution of Oxidative Values during Kinetic Studies on Olive Oil Oxidation in the Rancimat Test. American Chemical Sci. J., 91: 281-293.

Reza, F., Soodabeh, E. and Parvin, S. 2009. The effect of commercial refining steps on the rancidity measures of soybean and canola oils. Food Chem., 115: 933-938.

Rossi, M., Cristina, A., and Simona, R. 2007. Tocopherols and tocotrienols as free radical-scavengers in refined vegetable oils and their stability during deep-fat frying. Food Chemistry, 102: 812-817.

Shahidi, F. and Zhong, Y. 2005. Lipid Oxidation: Measurement Methods, In: F. Shahidi (Edit.), Bailey's Industrial Oil \& Fat Products, Wiley-Interscience, A john Wiley \& Sons, New Jersey, 357.

Suja, K.P., Jayalekshmy, A. and Arumughan, C. 2005. Antioxidant activity of sesame cake extract. Food chemistry 91: 213219.

Suliman, T.E.M.A., Jiang, J. and Liu, Y.F. 2013. Chemical refining of sunflower oil: effect on oil stability, total tocopherol, free fatty acids and colour. Int. J. Engineering Sci. Technol., 5(2): 449-454.

Szydłowska-Czerniak, A. 2013. Rapeseed and its products e sources of bioactive compounds: a review of their characteristics and analysis. Critical Reviews in Food Sci. Nutrition, 53: 307330.

Szydłowska-Czerniak, A., Karlovits, G., Dianoczki, C., Recseg, K. and Szłyk, E. 2008. Comparison of two analytical methods for assessing antioxidant capacity of rapeseed and olive oils. $J$. the American Oil Chemists' Society, 85:141-149.

Taylor, D. R. 2005. Bleaching. In: "Bailey's 
Industrial Oil and Fat Products", (Ed.)" Shahidi, F. John Wiley and Sons Publication, Hoboken, NJ,: 285-339.

Wei, J., Chen, L., Qiu, X.Y., Hu, W.J., Sun, H., Chen, X.L., Bai, Y.Q., Gu, X.Y., Wang, C.L.,Chen, H., Hu, R.B., Zhang, H. and Shen, G.X. 2015. Optimizing refining temperatureto reduce the loss of essential fatty acids and bioactive compounds in tea seedoil. Food and Bioproducts Processing, 94: 136-146.
Wilson, J., and Qian, M. 2002.Free radical scavenging properties of wheat extracts. J. Agri. Food Chem., 50: 16191624.

Zulkurnain, M., Lai, O.M., Latip, R.A., Nehdi, I.A., Ling, T.C., and Tan, C.P. 2012. The effects of physical refining on the formation of 3monochloropropane-1,2-diol esters in relation to palm oil minor components. Food Chem., 135(2): 799-805.

Yu, L., Haley, S., Perret, J., Harris, M.,

\section{How to cite this article:}

Adel Abd EL-Razek Mohdaly, Khaled Abd El-Hameed Seliem, Abd EL-Moneam Maher Abu EL-Hassan, Awad Abdel Tawab Mahmoud. 2017. Effect of Refining Process on the Quality Characteristics of Soybean and Cottonseed Oils. Int.J.Curr.Microbiol.App.Sci. 6(1): 207-222. doi: http://dx.doi.org/10.20546/ijcmas.2017.601.026 